\title{
TRIM proteins in blood cancers
}

\author{
Lisa J. Crawford $^{1}$ - Cliona K. Johnston ${ }^{1}$ - Alexandra E. Irvine ${ }^{1}$
}

Received: 13 October 2017 / Accepted: 17 October 2017 / Published online: 6 November 2017

(C) The Author(s) 2017. This article is an open access publication

\begin{abstract}
Post-translational modification of proteins with ubiquitin plays a central role in regulating numerous cellular processes. E3 ligases determine the specificity of ubiquitination by mediating the transfer of ubiquitin to substrate proteins. The family of tripartite motif (TRIM) proteins make up one of the largest subfamilies of E3 ligases. Accumulating evidence suggests that dysregulation of TRIM proteins is associated with a variety of diseases. In this review we focus on the involvement of TRIM proteins in blood cancers.
\end{abstract}

Keywords TRIM proteins $\cdot$ Ubiquitin $\cdot$ E3 ligase $\cdot$

Leukaemia $\cdot$ Lymphoma $\cdot$ Multiple myeloma

\section{Introduction}

Ubiquitination is a post-translational modification involving the covalent conjugation of one or more ubiquitin molecules to a substrate protein. The attachment of ubiquitin to a protein is important for the regulation of many cellular processes; it can mark a protein for degradation through the $26 \mathrm{~S}$ proteasome, modify interactions with other proteins, alter cellular localisation or affect activity. The process of ubiquitination is catalysed by the sequential action of three types of enzymes. An E1 enzyme activates ubiquitin and transfers it to an E2 conjugating enzyme, E2 enzymes then work in conjunction with E3 ubiquitin ligases to transfer ubiquitin to a target

Alexandra E. Irvine

s.irvine@qub.ac.uk

1 Centre for Cancer Research and Cell Biology, Queen's University Belfast, 97 Lisburn Road, Belfast BT9 7BL, UK protein. It is generally accepted that E3 ligases are responsible for substrate recognition and therefore confer specificity to the system (Yau and Rape 2016). Over 600 E3 ligases have been characterised in humans and are classified into 3 different classes: homologous to E6-AP carboxyl terminus (HECT), really interesting new gene (RING) and RING-betweenRING (RBR) (Buetow and Huang 2016). RING proteins are the largest class of E3 ligases and among them the tripartite motif (TRIM) family of proteins represent the largest subfamily of RINGs. TRIM proteins are involved in many biological processes including transcriptional regulation, cell proliferation and differentiation, intracellular signalling, apoptosis and immune signalling. Thus, it is not surprising that alterations of TRIM proteins are associated with a variety of pathologies including developmental disorders, inflammatory diseases and cancers. This review will provide an overview of the TRIM family and discuss alterations in TRIM proteins that are implicated in blood cancers.

\section{TRIM family overview}

TRIM proteins, also referred to as RBBC proteins, are characterised by the presence of an N-terminal tripartite or RBBC motif comprised of a RING domain, either one or two B-boxes (B1 and B2), and a coiled-coil (CC) domain, followed by a highly variable C-terminal domain (Reymond et al. 2001; Torok and Etkin 2001). To date, more than 70 TRIM family members have been identified and these are categorised into 11 subgroups (C-I-C-XI) based on the type of C-terminal domain present (Short and Cox 2006; Ozato et al. 2008); a number of TRIMs lacking a RING domain remain unclassified (Fig. 1). Based on the presence of a RING domain, the majority of TRIMs are defined as E3 ligases (Meroni and Diez-Roux 2005). However it should be noted that the ability to mediate 


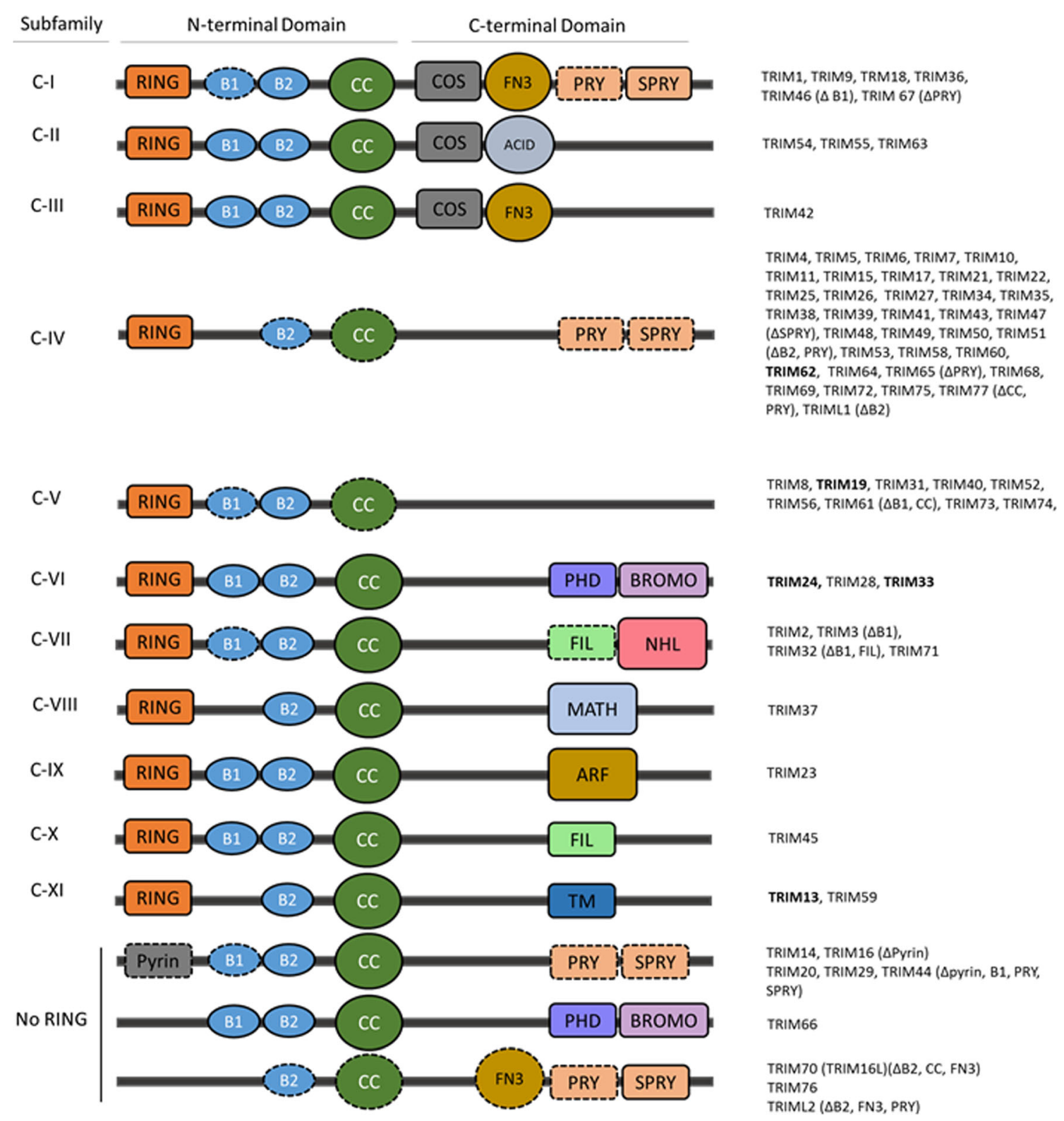

Fig. 1 Structural classification of tripartite motif (TRIM) family proteins. The majority of TRIM proteins contain an $\mathrm{N}$-terminal RING domain, one or two B-box domains (B1, B2) and a coiled-coil domain (CC) and are classified into 11 subfamilies (C-I - C-XI) based on a variable C-terminal domain; there is an additional unclassified group lacking a RING domain. Some family members lack one or more domain as denoted in

the conjugation of the ubiquitin-like modifications, SUMO and ISG15, is also attributed to a small number of TRIMs (Zou and Zhang 2006; Chu and Yang 2011). The RING domain is a specialised type of zinc finger that confers E3 ligase activity by binding to an ubiquitin-loaded E2 enzyme and promoting the transfer of ubiquitin to a target protein. The B-box domains, in common with the RING domain, are zinc fingers, however, their structural and functional role is less well defined. It has been suggested that due to similarities to the RING domain, they could enhance the E3 ligase activity and even confer E3 brackets and by a dashed outline. TRIMs included in this review are in bold. Abbreviations: ACID - acid-rich region, ARF - ADPribosylation factor family domain, BROMO - bromodomain, COS cos-box, FIL - filamin-type I G domain, FN3 - fibronectin type III repeat, MATH - meprin and TRAF-homology domain, NHL - NCL1, HT2A and LIN41 domain, PHD - PHD domain, PRY - PRY domain, SPRY - SPRY domain, TM - transmembrane region

ligase activity to RINGless TRIMs, as is the case for TRIM16 (Bell et al. 2012). The coiled-coil domain mediates oligomerisation, that is homo-dimerisation and potentially higher order oligomerisation, a process believed to be required for their function and E3 ligase activity (Esposito et al. 2017). In addition to homo-oligomerisation, there are increasing reports of hetero-oligomerisation between TRIMs, particularly among closely related family members. This is thought to increase the diversity of substrate specificity (Napolitano and Meroni 2012). The variable C-terminal region of TRIM 
proteins is predominantly responsible for substrate recognition and cellular localisation (Micale et al. 2012). The most prevalent C-terminal is the PRY-SPRY domain found in subfamilies $\mathrm{C}-\mathrm{I}$ and $\mathrm{C}-\mathrm{IV}$, this domain is common in immune signalling proteins (James et al. 2007). Other common C-terminal domains include a COS box found in subfamilies C-I, C-II and C-III and a fibronectin type III (FN3) domain found in subfamilies C-I and C-III.

\section{TRIM proteins in blood cancers}

TRIM proteins function in a broad range of cellular processes and there is accumulating evidence implicating members of the TRIM family in the development and progression of various tumour types. A number of TRIM proteins are linked to the development of blood cancers, through chromosomal translocations or dysregulated expression, acting as either a tumour suppressor or oncogene, depending on the cell type. The involvement of TRIM proteins in the aetiology of blood cancers is summarised below and in Table 1.

\section{TRIM62}

TRIM62 is a member of the largest subfamily of TRIMs, C.IV, which contain a C-terminal PRY/SPRY domain. TRIM62 has been reported to act as a putative tumour suppressor in a number of cancers, including acute myeloid leukaemia (AML). AML is heterogeneous malignancy characterised by the clonal proliferation of immature myeloid cells. It is commonly classified based on cytogenetic and molecular abnormalities
(Vardiman et al. 2009). Quintas-Cardama et al. (2015) evaluated TRIM62 protein expression in a large cohort of AML patients at diagnosis. They found that TRIM62 expression was significantly lower in CD34+ cells from AML patients compared to healthy volunteers and low levels were significantly associated with a shorter duration of remission and shorter event-free and overall survival. These effects were particularly notable among patients defined as having cytogenetically normal AML (CN-AML). In this subset of patients a number of molecular aberrations have been found to play an important role in prognosis, this study found that TRIM62 represents an additional independent adverse prognostic factor in CN-AML. While the mode of action of TRIM62 has not been defined, low TRIM62 levels were associated with altered expression of proteins involved in stem cell homeostasis, cell motility and adhesion, hypoxia and apoptosis.

\section{TRIM19}

TRIM19 is more commonly known as the promyelocytic leukaemia (PML) protein as it was originally identified as part of a balanced translocation with retinoic acid receptor $\alpha$ (RAR $\alpha)$ that specifically occurs in acute promyelocytic leukaemia (APL) (de The et al. 1991). It belongs to the C-V subfamily of TRIM proteins, which lack any obvious domain other than R-B1-B2-CC domain that is common to all TRIMs. In normal cells, PML is essential for the formation of distinct nuclear structures known as PML nuclear bodies (PML-NB). These are dynamic structures that are triggered in response to various cellular stresses. PML-NBs are implicated in the regulation of a wide range of cellular processes including transcriptional
Table 1 Alterations in TRIM family members in blood cancers

\begin{tabular}{lllll}
\hline TRIM & Blood cancer & Alteration & Suggested effect & Reference \\
\hline TRIM13 & CLL & Gene Deletion & Tumour suppressor & Kapanadze et al. 2000 \\
& MM & Gene Deletion & Oncogene & Gatt et al. 2013 \\
TRIM19 & APL & Translocation:RAR $\alpha$ & Tumour suppressor & Chen and Chen 1992 \\
& B-ALL & Translocation:PAX5 & Tumour suppressor & Kurahashi et al. 2011 \\
& Lymphoma & Reduced expression & Tumour suppressor & Gurrieri et al. 2004 \\
& CML & Overexpression & Oncogene & Ito et al. 2008 \\
TRIM24 & AML & Overexpression & Oncogene & Gandini et al. 2002 \\
& EMS & Translocation:FGFR1 & Oncogene & Jackson et al. 2010 \\
TRIM33 & CMML & Reduced expression & Tumour suppressor & Aucagne et al. 2011 \\
& B-ALL & N/A & Oncogene & Wang et al. 2015 \\
& MM & Reduced expression & Tumour suppressor & Johnston et al. 2017 \\
TRIM62 & AML & Reduced expression & Tumour suppressor & Quintas-Cardama et al. 2015 \\
\hline
\end{tabular}

$A M L$, acute myeloid leukaemia; $A P L$ acute promyelocytic leukaemia; $B-A L L$ B cell acute lymphocytic leukaemia; $C L L$ chronic lymphocytic leukaemia; $C M L$ chronic myeloid leukaemia; $C M M L$ chronic myelomonocytic leukaemia; EMS 8p11 myeloproliferative syndrome; FGFR1 fibroblast growth factor receptor 1; N/A not applicable; $P A X 5$ paired box 5; RAR $\alpha$ retinoic acid receptor $\alpha$ 
regulation, cell cycle control, apoptosis, senescence, DNA damage response and anti-viral response (Bernardi and Pandolfi 2007). There are at least 7 protein isoforms of PML which all share an identical N-terminal TRIM motif and have varying $\mathrm{C}$-terminals. However, the majority of isoforms contain a nuclear localisation signal and SUMO-interacting motif (SIM) which is critical for PML-NB formation (Li et al. 2017).

\section{TRIM19 in acute promyelocytic leukaemia}

Acute promyelocytic leukaemia (APL) is a distinct subtype of AML characterised by the accumulation of abnormal promyelocytes in the bone marrow. In the majority of patients $(>98 \%)$, APL is associated with a balanced reciprocal chromosomal translocation, $\mathrm{t}(15 ; 17)$, which produces the PMLRAR $\alpha$ fusion protein (de The et al. 1991). RAR $\alpha$ is a nuclear receptor that regulates transcription in a ligand-dependent manner. When bound to retinoic acid (RA), RAR $\alpha$ induces the expression of genes promoting myeloid differentiation and conversely in the absence of RA, RAR $\alpha$ represses the transcription of target genes. The PML-RAR $\alpha$ fusion protein retains the N-terminal multimerisation domain of PML and the C-terminal DNA and ligand-binding domain of RAR $\alpha$ and acts in a dominant negative manner to disrupt the function of both proteins (Chen and Chen 1992). Through the formation of PML-RAR $\alpha /$ PML heterodimers, PML-RAR $\alpha$ antagonises the formation of PML-NBs. In addition, PMLRAR $\alpha$ acts as a transcriptional suppressor of RAR $\alpha$ function, thus inducing a block in differentiation of promyelocytes. Historically, APL conferred a poor prognosis, however, the introduction of therapies specifically targeting PML-RAR $\alpha$ has dramatically improved outcomes. Two targeted therapies, all-trans retinoic acid (ATRA) and arsenic trioxide (ATO), each act on one partner of the PML-RAR fusion protein (Zhou et al. 2007). ATRA induces dissociation of corepressor complexes from the RAR $\alpha$ moiety and subsequently induces proteasome-mediated degradation of PML-RAR $\alpha$. This promotes differentiation of leukaemic promyelocytes into mature granulocytes. ATO on the other hand binds to PML and PML-RAR $\alpha$ resulting in sumoylation which in turn promotes polyubiquitination and degradation of PML-RAR $\alpha$ (Tomita et al. 2013). There is a high degree of synergy between these targeted agents and they are commonly incorporated into APL induction therapies (Abaza et al. 2017; Platzbecker et al. 2017).

\section{TRIM19 in other haematological malignancies}

In addition to its role in APL, PML exhibits dysregulated expression in other haematopoietic malignancies. PML has been found as a translocation partner with the transcription factor paired box 5 (PAX5) [t(9;15)] in some cases of B-cell acute lymphocytic leukaemia (B-ALL). Similar to PML-
RAR $\alpha$, the PAX-PML fusion protein acts in a dominant negative manner to inhibit PAX5 transcriptional activity and impair the formation of PML-NBs (Kurahashi et al. 2011). Furthermore, reduced protein expression of PML has been reported in non-Hodgkin's lymphoma (Gurrieri et al. 2004). A role for PML in lymphoma was further demonstrated using mouse models of myc-driven B-lymphoma. Loss of one allele of E6AP, an E3 ligase for PML, restored PML levels and induced cellular senescence, leading to a significant delay in Myc-induced lymphagenesis.

Overall, these studies are in agreement with PML's widely reported function as a tumour suppressor in a variety of both haematopoietic and solid tumours (Gamell et al. 2014), however, chronic myeloid leukaemia (CML) is an exception to this. CML is a myeloproliferative disorder that, in common with APL, is characterised by a specific chromosomal translocation, in this case $t(9 ; 22)$, which gives rise to the tyrosine kinase BCR-ABL. The translocation originates in haematopoietic stem cells that can self-renew, proliferate and differentiate leading to an excessive accumulation of myeloid cells. Tyrosine kinase inhibitors (TKIs) target the kinase activity of BCR-ABL and have transformed the treatment of CML, however, the persistence of TKI-resistant stem cells remains one of the major obstacles to eradicating the disease (Holyoake and Vetrie 2017). Ito et al. (2008) found that PML was required for the maintenance of both normal haematopoietic stem cells and leukaemic stem cells expressing BCR-ABL. Moreover, they reported that low expression of PML in CML blasts was associated with improved overall survival. A number of laboratory studies point to the potential of using ATO in combination with TKIs to target CML stem cells (Naka et al. 2010) Fig. 2.

\section{TRIM33}

TRIM33, also known as transcriptional intermediary factor $1 \gamma$ (TIF1 $\gamma$ ), is a nuclear protein that belongs to the C-VI subfamily of TRIM proteins containing a C-terminal tandem plant homeodomain (PHD) and bromodomain module. Members of this subfamily also belong to the TIF1 family, which are involved in chromatin-mediated transcriptional regulation. The PHDbromodomain module interacts with post-translationally modified histone tails to recruit TRIM33 to chromatin and stimulate its E3 ligase activity (Agricola et al. 2011). TRIM33 is implicated in the regulation of many aspects of haematopoiesis and interacts with key transcriptional regulators of haematopoiesis, such as PU.1, TAL1 and SMAD4. The importance of TRIM33 in haematopoiesis was first reported in a zebrafish model demonstrating that loss of TRIM33 disrupts both embryonic and adult haematopoiesis and is required for normal erythroid development (Ransom et al. 2004). Subsequent studies have found that TRIM33 is involved in the regulation of haematopoietic stem 
Loss of Tumour Suppressor

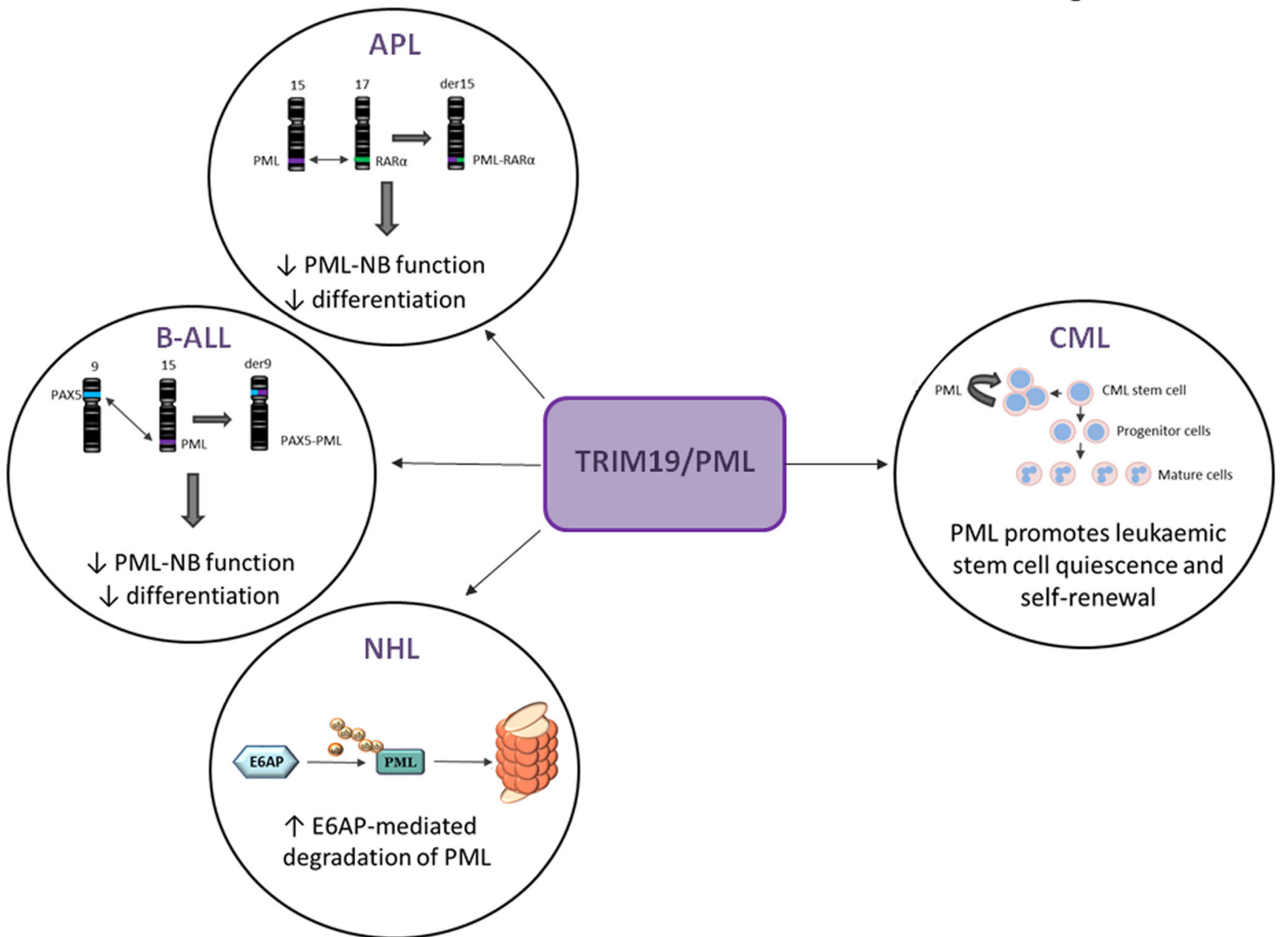

Fig. 2 TRIM19/PML exerts cell type dependent effects on blood cancers. In acute promyelocytic leukaemia (APL), B cell acute lymphoblastic leukaemia (B-ALL) and non-Hodgkin's lymphoma (NHL), the tumour suppressive activity of PML is lost. The majority of patients with APL harbour the $\mathrm{t}(15 ; 17)$ translocation resulting in a promyelocytic leukaemia - retinoic acid receptor $\alpha$ (PML-RAR $\alpha)$ gene and protein. This disrupts the normal function of both proteins leading to impaired PML-nuclear bodies (PML-NB) formation and a block in

cells (HSC), granulomonopoiesis and macrophage differentiation, transcriptional elongation of erythroid genes (Bai et al. 2010, 2013) and plays a key role in the recruitment of myeloid cells to sites of inflammation (Demy et al. 2017). It is therefore not surprising that TRIM33 has also been found to be dysregulated in a number of haematological malignancies. While TRIM33 is largely considered to exhibit tumour suppressor activity, it is also reported to act as oncogene depending on the cell type involved.

\section{TRIM33 in chronic myelomonocytic leukaemia}

Chronic myelomonocytic leukaemia (CMML) is a clonal HSC malignancy characterised by the expansion of the granulo-monocytic compartment in the bone marrow, differentiation. In some cases of B-ALL, PML is found translocated to the transcription factor paired box 5 (PAX5), again disrupting the formation of PML-NB and leading to decreased differentiation. In NHL reduced protein expression of PML is seen due to increased E6APmediated proteasomal degradation of PML. Conversely, PML is seen to play an oncogenic role in chronic myeloid leukaemia (CML), where it has been found to be important for self-renewal and quiescence in leukaemic stem cells

peripheral blood and spleen. CMML is generally associated with advancing age and has a median age at diagnosis of 70 (Padron et al. 2015). Using a conditional knockout model, Aucagne et al. (2011) demonstrated that loss of TRIM33 in mouse HSCs favoured the expansion of granulo-monocytic progenitors and older TRIM33-deficient mice exhibited features of CMML. Furthermore, they demonstrated that TRIM33 was downregulated in 35\% of CMML patients. Low levels of TRIM33 in CMML patients were due to hypermethylation of the gene promoter and expression could be restored using the hypomethylating agent decitabine. The hypomethylating agents azacitidine and decitabine are commonly used to treat older patients with CMML (Alfonso et al. 2017) and have recently been shown to confer a significant survival advantage to CMML patients in the first year after 
diagnosis (Zeidan et al. 2017). Future studies are warranted to investigate whether TRIM33 could be used as a biomarker of response to these agents in CMML.

\section{TRIM33 in B-cell acute lymphoblastic leukaemia}

In contrast to the role of TRIM33 as a tumour suppressor in CMML, Wang et al. (2015) found that TRIM33 acts as an oncogene in B-cell acute lymphoblastic leukaemia (B-ALL), a malignancy of immature B-cells that predominantly affects young children. TRIM33 was identified during an RNAi screen for essential chromatin regulators in B-ALL. In murine B-ALL cells, it was demonstrated that TRIM33 is recruited by PU.1 to select lineage-specific enhancers and inhibits apoptosis in these cells by blocking activation of the pro-apoptotic gene Bim. TRIM33-deficient mice displayed selective loss of CD19 and B220 B lymphoid cells suggesting that TRIM33 is also required for normal B cell development. While the authors propose that TRIM33 is essential for the survival of all B cell neoplasms, there is conflicting evidence to suggest that TRIM33 has opposing effects in Multiple Myeloma (MM). MM is characterised by the clonal proliferation of plasma cells, which are terminally differentiated B cells. TRIM33 is located on chromosome 1p13.1, a common deleted region seen in MM patients (Li et al. 2016). Low expression of TRIM33 in MM has previously been found to be significantly associated with poor clinical outcome (Shaughnessy et al. 2007). In concert with this, we have recently proposed that TRIM33 acts as a tumour suppressor in MM (Johnston et al. 2017 and unpublished observations). There are well recognised functional and transcriptional differences that distinguish $\mathrm{B}$ cells from more differentiated antibody secreting plasma cells and this may account for the opposing roles of TRIM33 suggested in B-ALL versus MM cells (Recaldin and Fear 2016; Nutt et al. 2015) Fig. 3.

\section{TRIM24}

TRIM24, also known as TIF $1 \alpha$, is also a member the C-VI subfamily of TRIM proteins and the TIF1 family. In common with TRIM33, TRIM24 is involved in chromatin-dependent regulation of transcription, however, they differ in their specificity for histone modifications (Herquel et al. 2011a, b). TRIM24 regulates cellular transcription by interacting with nuclear receptors such as retinoic acid and is also involved in controlling the stability of the tumour suppressor p53. Like many other TRIM proteins, TRIM24 has been reported to exhibit both tumour suppressor and oncogenic properties in a cell type dependent context. Due to its interactions with retinoic acid receptors, it has been postulated that TRIM24 may play a role in myeloid differentiation. While there is no direct evidence for this, dysregulated expression of TRIM24 has been reported in

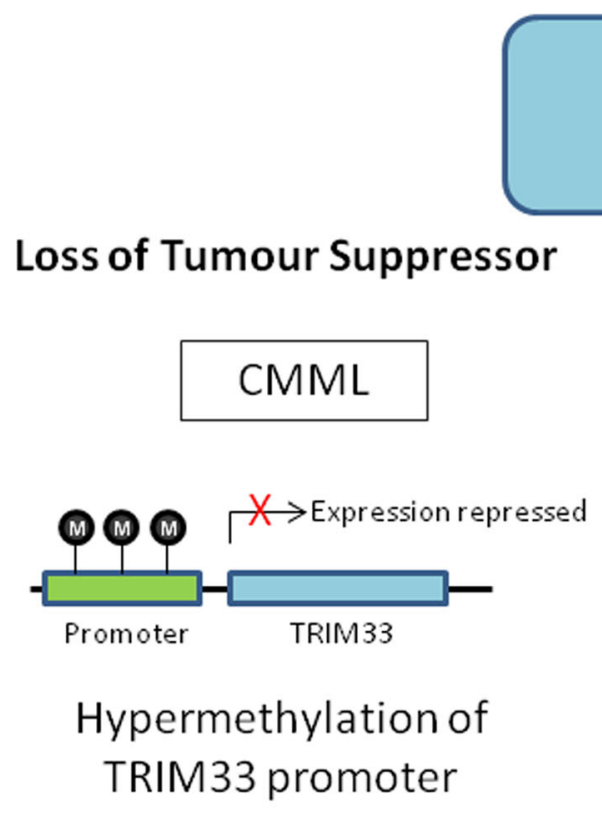

TRIM33

\section{Loss of Tumour Suppressor}

Fig. 3 The dual role of TRIM33 in the regulation of blood cancers. In chronic myelomonocytic leukaemia (CMML) TRIM33 is epigenetically silenced through increased methylation of its promoter in approximately a third of patients, leading to

\section{Oncogene}

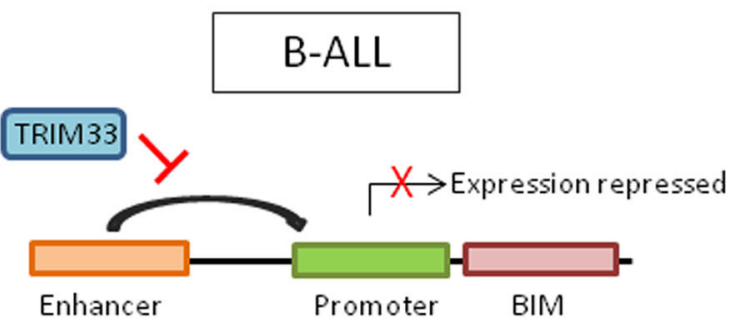

TRIM33 blocks activation of BIM apoptosis

loss of tumour suppressor activity. Conversely, TRIM33 has been found to be essential for the survival of B cell acute lymphoblastic leukaemia (B-ALL) cells by blocking enhancer mediated activation of the proapoptotic gene BIM 
AML. Gandini et al. (2002) found higher expression of TRIM24 in some subtypes of AML and they report significantly overexpressed TRIM24 in AML that has transformed from a pre-leukaemic haematological disorder known as myelodysplastic syndrome (MDS) but not in untransformed MDS. TRIM24 has also been implicated in recurrent chromosomal rearrangements associated with a neoplasm known as 8 p11 myeloproliferative syndrome or EMS (Belloni et al. 2005). This is a rare myeloproliferative neoplasm associated with translocation of Fibroblast Growth Factor Receptor 1 (FGFR1) on chromosome $8 \mathrm{p} 11$ to one of at least 14 partner genes, resulting in constitutive tyrosine kinase activity (Jackson et al. 2010). EMS is characterized by eosinophilia, T-cell proliferation and frequent progression to AML (Patnaik et al. 2010).

\section{TRIM13}

TRIM13, also known as ret finger protein 2 (RFP2), belongs to the C-XI subfamily containing a RING finger, one B-box domain, a coiled-coil domain and a C-terminal transmembrane domain. It localises to endoplasmic reticulum (ER) membranes via its transmembrane domain and regulates the turnover of ER-associated degradation (ERAD) substrates. TRIM13 was initially identified as a putative tumour suppressor gene in B cell chronic lymphocytic leukaemia (B-CLL) (Kapanadze et al. 2000). It is located on chromosome 13 within a minimum commonly deleted region (13q14) that is frequently deleted in CLL and also lost in other B cell malignancies such as MM, mantle cell lymphoma (MCL) and diffuse large B cell lymphoma (DLBCL). While TRIM13 was first identified as a candidate tumour suppressor in B-CLL, there are conflicting reports on its relevance. Following initial identification, a number of studies have excluded TRIM13 as a tumour suppressor gene in B-CLL (Rondeau et al. 1999; Bullrich et al. 2001). However, Baranova et al. (2003) subsequently reported downregulated expression of TRIM13 in CLL patients at advanced stage of disease in comparison to expression at diagnosis, suggesting that it does exhibit properties of a tumour suppressor. In MM, deletion of chromosome $13 \mathrm{q}$, particularly $13 \mathrm{q} 14$, is present in approximately half of patients at diagnosis and is associated with a poor clinical outcome. Gatt et al. (2013) investigated the role of TRIM13 in the pathogenesis of MM using a loss-of-function approach. Unexpectedly they found that TRIM13 downregulation led to decreased survival and proliferation of MM cell lines, along with inhibition of the NFKB pathway and proteasome activity.

\section{Concluding remarks}

As described in this review, TRIM proteins can positively or negatively regulate the initiation or progression of blood cancers by affecting processes such as transcriptional regulation, cell cycle control, differentiation and apoptosis. In fact, many of the TRIM proteins described can exhibit a dual role either as an oncogene or tumour suppressor, depending on the context. For example, loss of the normal function of TRIM19/PML through translocation or E6AP-mediated degradation is implicated in the pathogenesis of APL, B-ALL and lymphoma, whereas in CML low TRIM19 expression correlates with improved overall survival. This demonstrates that the role of TRIM proteins in the regulation of both normal haematopoiesis and leukaemogenesis is complex and often cell type specific, highlighting the need to investigate the biological relevance of individual TRIMs in the appropriate cell type. To add a further layer of complexity, a number of TRIM proteins are known to heterodimerise with other TRIMs, which is thought to enhance their E3 ligase activity or diversify substrate specificity. Two TRIMs, TRIM24 and TRIM33, described in isolation in this review are known to form a complex that co-operatively acts in tumour suppression in hepatocellular cancer cells (Herquel et al. 2011b). Investigation of the role of this heterodimer in relevant blood cancers could reveal additional roles in the promotion or prevention of oncogenesis. Over half of TRIM family members, including those discussed here, have been shown to play an important role in regulating the innate immune response. The immune system is known to be involved in shaping the evolution and biology of blood cancers and as our understanding of the role of TRIM proteins in immunity increases, there may be more TRIMs identified that indirectly participate in tumour development and progression. Given their involvement in a variety of diseases, TRIM proteins represent attractive therapeutic targets. The ubiquitin proteasome system is already established as an important therapeutic target in blood cancers. Inhibition of proteasome activity with bortezomib or carfilzomib is widely used in all aspects of anti-MM therapies (Landgren and Iskander 2017). Furthermore, there is increasing interest in targeting individual E3 ligases either through inhibiting or altering E3 ligase activity The successful use of ATO to treat APL represents the first use of a TRIM-specific targeted therapy. As our knowledge of the role of TRIM family members in blood cancers increases, it is likely that further opportunities for the development of targeted therapies will emerge.

Open Access This article is distributed under the terms of the Creative Commons Attribution 4.0 International License (http:// creativecommons.org/licenses/by/4.0/), which permits unrestricted use, distribution, and reproduction in any medium, provided you give appropriate credit to the original author(s) and the source, provide a link to the Creative Commons license, and indicate if changes were made. 


\section{References}

Abaza Y, Kantarjian H, Garcia-Manero G, Estey E, Borthakur G, Jabbour E, Faderl S, O'Brien S, Wierda W, Pierce S, Brandt M, McCue D, Luthra R, Patel K, Kornblau S, Kadia T, Daver N, DiNardo C, Jain N, Verstovsek S, Ferrajoli A, Andreeff M, Konopleva M, Estrov Z, Foudray M, McCue D, Cortes J, Ravandi F (2017) Long-term outcome of acute promyelocytic leukemia treated with all-trans-retinoic acid, arsenic trioxide, and gemtuzumab. Blood 129:1275-1283

Agricola E, Randall RA, Gaarenstroom T, Dupont S, Hill CS (2011) Recruitment of TIF1gamma to chromatin via its PHD fingerbromodomain activates its ubiquitin ligase and transcriptional repressor activities. Mol Cell 43:85-96

Alfonso A, Montalban-Bravo G, Takahashi K, Jabbour EJ, Kadia T, Ravandi F, Cortes J, Estrov Z, Borthakur G, Pemmaraju N, Konopleva M, Bueso-Ramos C, Pierce S, Kantarjian H, GarciaManero G (2017) Natural history of chronic myelomonocytic leukemia treated with hypomethylating agents. Am J Hematol 92:599-606

Aucagne R, Droin N, Paggetti J, Lagrange B, Largeot A, Hammann A, Bataille A, Martin L, Yan KP, Fenaux P, Losson R, Solary E, Bastie JN, Delva L (2011) Transcription intermediary factor 1gamma is a tumor suppressor in mouse and human chronic myelomonocytic leukemia. J Clin Invest 121:2361-2370

Bai X, Kim J, Yang Z, Jurynec MJ, Akie TE, Lee J, LeBlanc J, Sessa A, Jiang H, DiBiase A, Zhou Y, Grunwald DJ, Lin S, Cantor AB, Orkin SH, Zon LI (2010) TIF1 gamma controls erythroid cell fate by regulating transcription elongation. Cell 142:133-143

Bai X, Trowbridge JJ, Riley E, Lee JA, DiBiase A, Kaartinen VM, Orkin SH, Zon LI (2013) TiF1-gamma plays an essential role in murine hematopoiesis and regulates transcriptional elongation of erythroid genes. Dev Biol 373:422-430

Baranova A, Hammarsund M, Ivanov D, Skoblov M, Sangfelt O, Corcoran M, Borodina T, Makeeva N, Pestova A, Tyazhelova T, Nazarenko S, Gorreta F, Alsheddi T, Schlauch K, Nikitin E, Kapanadze B, Shagin D, Poltaraus A, Ivanovich Vorobiev A, Zabarovsky E, Lukianov S, Chandhoke V, Ibbotson R, Oscier D, Einhorn S, Grander D, Yankovsky N (2003) Distinct organization of the candidate tumor suppressor gene RFP2 in human and mouse: multiple mRNA isoforms in both species- and human-specific antisense transcript RFP2OS. Gene 321:103-112

Bell JL, Malyukova A, Holien JK, Koach J, Parker MW, Kavallaris M, Marshall GM, Cheung BB (2012) TRIM16 acts as an E3 ubiquitin ligase and can heterodimerize with other TRIM family members. PLoS One 7:e37470

Belloni E, Trubia M, Gasparini P, Micucci C, Tapinassi C, Confalonieri S, Nuciforo P, Martino B, Lo-Coco F, Pelicci PG, Di Fiore PP (2005) 8p11 myeloproliferative syndrome with a novel $\mathrm{t}(7 ; 8)$ translocation leading to fusion of the FGFR 1 and TIF1 genes. Genes Chromosomes Cancer 42:320-325

Bernardi R, Pandolfi PP (2007) Structure, dynamics and functions of promyelocytic leukaemia nuclear bodies. Nat Rev Mol Cell Biol 8:1006-1016

Buetow L, Huang DT (2016) Structural insights into the catalysis and regulation of E3 ubiquitin ligases. Nat Rev Mol Cell Biol 17:626-642

Bullrich F, Fujii H, Calin G, Mabuchi H, Negrini M, Pekarsky Y, Rassenti L, Alder H, Reed JC, Keating MJ, Kipps TJ, Croce CM (2001) Characterization of the 13q14 tumor suppressor locus in CLL: identification of ALT1, an alternative splice variant of the LEU2 gene. Cancer Res 61:6640-6648

Chen Z, Chen SJ (1992) RARA and PML genes in acute promyelocytic leukemia. Leuk Lymphoma 8:253-260

Chu Y, Yang X (2011) SUMO E3 ligase activity of TRIM proteins. Oncogene 30:1108-1116

Demy DL, Tauzin M, Lancino M, Le Cabec V, Redd M, Murayama E, Maridonneau-Parini I, Trede N, Herbomel P (2017) Trim33 is essential for macrophage and neutrophil mobilization to developmental or inflammatory cues. J Cell Sci 130:2797-2807

Esposito D, Koliopoulos MG, Rittinger K (2017) Structural determinants of TRIM protein function. Biochem Soc Trans 45:183-191

Gamell C, Jan Paul P, Haupt Y, Haupt S (2014) PML tumour suppression and beyond: therapeutic implications. FEBS Lett 588:2653-2662

Gandini D, De Angeli C, Aguiari G, Manzati E, Lanza F, Pandolfi PP, Cuneo A, Castoldi GL, del Senno L (2002) Preferential expression of the transcription coactivator HTIF1alpha gene in acute myeloid leukemia and MDS-related AML. Leukemia 16:886-893

Gatt ME, Takada K, Mani M, Lerner M, Pick M, Hideshima T, Carrasco DE, Protopopov A, Ivanova E, Sangfelt O, Grander D, Barlogie B, Shaughnessy JD, Anderson KC, Carrasco DR (2013) TRIM13 (RFP2) downregulation decreases tumour cell growth in multiple myeloma through inhibition of NF kappa B pathway and proteasome activity. Br J Haematol 162:210-220

Gurrieri C, Capodieci P, Bernardi R, Scaglioni PP, Nafa K, Rush LJ, Verbel DA, Cordon-Cardo C, Pandolfi PP (2004) Loss of the tumor suppressor PML in human cancers of multiple histologic origins. J Natl Cancer Inst 96:269-279

Herquel B, Ouararhni K, Davidson I (2011a) The TIF1 $\alpha$-related cofactors couple chromatin modifications to transcriptional regulation, signalling and tumor suppression. Transcription 22:231-236

Herquel B, Ouararhni K, Khetchoumian K, Ignat M, Teletin M, Mark M, Bechade G, Van Dorsselaer A, Sanglier-Cianferani S, Hamiche A, Cammas F, Davidson I, Losson R (2011b) Transcription cofactors TRIM24, TRIM28, and TRIM33 associate to form regulatory complexes that suppress murine hepatocellular carcinoma. Proc Natl Acad Sci U S A 108:8212-8217

Holyoake TL, Vetrie D (2017) The chronic myeloid leukaemia stem cell: stemming the tide of persistence. Blood 129:1595-1606

Ito K, Bernardi R, Morotti A, Matsuoka S, Saglio G, Ikeda Y, Rosenblatt J, Avigan DE, Teruya-Feldstein J, Pandolfi PP (2008) PML targeting eradicates quiescent leukaemia-initiating cells. Nature 453:1072-1078

Jackson CC, Medeiros LJ, Miranda RN (2010) 8p11 myeloproliferative syndrome: a review. Hum Pathol 41:461-476

James LC, Keeble AH, Khan Z, Rhodes DA, Trowsdale J (2007) Structural basis for PRYSPRY-mediated tripartite motif(TRIM) protein function. Proc Natl Acad Sci U S A 104:6200-6205

Johnston CK, Crawford LJ, Mills KI, Irvine AE (2017) TRIM33 is a potential tumor suppressor in multiple myeloma. Haematologica 102:501-502

Kapanadze B, Makeeva N, Corcoran M, Jareborg N, Hammarsund M, Baranova A, Zabarovsky E, Vorontsova O, Merup M, Gahrton G, Jansson M, Yankovsky N, Einhorn S, Oscier D, Grander D, Sangfelt O (2000) Comparative sequence analysis of a region on human chromosome 13q14, frequently deleted in B-cell chronic lymphocytic leukemia, and its homologous region on mouse chromosome 14. Genomics 70:327-334

Kurahashi S, Hayakawa F, Miyata Y, Yasuda T, Minami Y, Tsuzuki S, Abe A, Naoe T (2011) PAX5-PML acts as a dual dominant-negative form of both PAX5 and PML. Oncogene 30:1822-1830

Landgren O, Iskander K (2017) Modern multiple myeloma therapy: deep, sustained treatment response and good clinical outcomes. J Intern Med 281:365-382

Li F, Hu L, Xu Y, Li Z, Yi S, Gu Z, Li C, Hao M, Ru K, Zhan F, Zetterberg A, Yuan W, Cheng T, Qiu L (2016) Identification of characteristic and prognostic values of chromosome $1 \mathrm{p}$ abnormality by multi-gene fluorescence in situ hybridization in multiple myeloma. Leukemia 30:1197-1201

Li C, Peng Q, Wan X, Sun H, Tang J. (2017) C-terminal motifs in PML isoforms critically regulate PML-NB formation. J Cell Sci 130: 3496-3506

Meroni G, Diez-Roux G (2005) TRIM/RBCC, a novel class of 'single protein RING finger' E3 ubiquitin ligases. BioEssays : News and 
Reviews in Molecular, Cellular and Developmental Biology 27: $1147-1157$

Micale L, Chaignat E, Fusco C, Reymond A, Merla G (2012) The tripartite motif: structure and function. Adv Exp Med Biol 770:11-25

Naka K, Hoshii T, Hirao A (2010) Novel therapeutic approach to eradicate tyrosine kinase inhibitor resistant chronic myeloid leukemia stem cells. Cancer Sci 101:1577-1581

Napolitano LM, Meroni G (2012) TRIM family: pleiotropy and diversification through homomultimer and heteromultimer formation. IUBMB Life 64:64-71

Nutt SL, Hodgkin PD, Tarlinton DM, Corcoran LM (2015) The generation of antibody-secreting plasma cells. Nat Rev Immunol 15:160-171

Ozato K, Shin DM, Chang TH, Morse HC (2008) TRIM family proteins and their emerging roles in innate immunity. Nat Rev Immunol 8: 849-860

Padron E, Garcia-Manero G, Patnaik MM, Itzykson R, Lasho T, Nazha A, Rampal RK, Sanchez ME, Jabbour E, Al Ali NH, Thompson Z, Colla S, Fenaux P, Kantarjian HM, Killick S, Sekeres MA, List AF, Onida F, Komrokji RS, Tefferi A, Solary E (2015) An international data set for CMML validates prognostic scoring systems and demonstrates a need for novel prognostication strategies. Blood Cancer J 5:e333

Patnaik MM, Gangat N, Knudson RA, Keefe JG, Hanson CA, Pardanani A, Ketterling RP, Tefferi A (2010) Chromosome 8p11.2 translocations: prevalence, FISH analysis for FGFR1 and MYST3, and clinicopathologic correlates in a consecutive cohort of 13 cases from a single institution. Am J Hematol 85:238-242

Platzbecker U, Avvisati G, Cicconi L, Thiede C, Paoloni F, Vignetti M, Ferrara F, Divona M, Albano F, Efficace F, Fazi P, Sborgia M, Di Bona E, Breccia M, Borlenghi E, Cairoli R, Rambaldi A, Melillo L, La Nasa G, Fiedler W, Brossart P, Hertenstein B, Salih HR, Wattad M, Lubbert M, Brandts CH, Hanel M, Rollig C, Schmitz N, Link H, Frairia C, Pogliani EM, Fozz C, D'Arco AM, Di Renzo N, Cortelezzi A, Fabbiano F, Dohner K, Ganser A, Dohner H, Amadori S, Mandelli F, Ehninger G, Schlenk RF, Lo-Coco F (2017) Improved outcomes with retinoic acid and arsenic trioxide compared with retinoic acid and chemotherapy in non-high-risk acute promyelocytic leukemia: final results of the randomized Italian-German APL0406 trial. J Clin Oncol 35:605-612

Quintas-Cardama A, Zhang N, Qiu YH, Post S, Creighton CJ, Cortes J, Coombes KR, Kornblau SM (2015) Loss of TRIM62 expression is an independent adverse prognostic factor in acute myeloid leukemia. Clin Lymphoma Myeloma Leuk 15:115-127.e15

Ransom DG, Bahary N, Niss K, Traver D, Burns C, Trede NS, PaffettLugassy N, Saganic WJ, Lim CA, Hersey C, Zhou Y, Barut BA, Lin S, Kingsley PD, Palis J, Orkin SH, Zon LI (2004) The zebrafish moonshine gene encodes transcriptional intermediary factor 1gamma, an essential regulator of hematopoiesis. PLoS Biol 2:E237

Recaldin T, Fear DJ (2016) Transcription factors regulating B cell fate in the germinal centre. Clin Exp Immunol 183:65-75
Reymond A, Meroni G, Fantozzi A, Merla G, Cairo S, Luzi L, Riganelli D, Zanaria E, Messali S, Cainarca S, Guffanti A, Minucci S, Pelicci PG, Ballabio A (2001) The tripartite motif family identifies cell compartments. EMBO J 20:2140-2151

Rondeau G, Moreau I, Bezieau S, Cadoret E, Moisan JP, Devilder MC (1999) Exclusion of Leu1 and Leu2 genes as tumor suppressor genes in 13q14.3-deleted B-CLL. Leukemia 13:1630-1632

Shaughnessy JD Jr, Zhan F, Burington BE, Huang Y, Colla S, Hanamura I, Stewart JP, Kordsmeier B, Randolph C, Williams DR, Xiao Y, Xu H, Epstein J, Anaissie E, Krishna SG, Cottler-Fox M, Hollmig K, Mohiuddin A, Pineda-Roman M, Tricot G, van Rhee F, Sawyer J, Alsayed Y, Walker R, Zangari M, Crowley J, Barlogie B (2007) A validated gene expression model of high-risk multiple myeloma is defined by deregulated expression of genes mapping to chromosome 1. Blood 109:2276-2284

Short KM, Cox TC (2006) Subclassification of the RBCC/TRIM superfamily reveals a novel motif necessary for microtubule binding. J Biol Chem 281:8970-8980

de The H, Lavau C, Marchio A, Chomienne C, Degos L, Dejean A. (1991) The PML-RAR alpha fusion mRNA generated by the $t(15 ; 17)$ translocation in acute promyelocytic leukemia encodes a functionally altered RAR. Cell 66: 675-684

Tomita A, Kiyoi H, Naoe T (2013) Mechanisms of action and resistance to all-trans retinoic acid (ATRA) and arsenic trioxide (As2O 3) in acute promyelocytic leukemia. Int J Hematol 97:717-725

Torok M, Etkin LD (2001) Two B or not two B? Overview of the rapidly expanding B-box family of proteins. Differentiation; Research in Biological Diversity 67:63-71

Vardiman JW, Thiele J, Arber DA, Brunning RD, Borowitz MJ, Porwir A, Harris NL, Le Beau MM, Hellstrom-Lindberg E, Tefferi A, Bloomfield CD (2009) The 2008 revision of the World Health Organization (WHO) classification of myeloid neoplasms and acute leukemia: rationale and important changes. Blood 114:937-951

Wang E, Kawaoka S, Roe JS, Shi J, Hohmann AF, Xu Y, Bhagwat AS, Suzuki Y, Kinney JB, Vakoc CR (2015) The transcriptional cofactor TRIM33 prevents apoptosis in B lymphoblastic leukemia by deactivating a single enhancer. elife 4:e06377

Yau R, Rape M (2016) The increasing complexity of the ubiquitin code. Nat Cell Biol 18:579-586

Zeidan AM, Hu X, Long JB, Wang R, Ma X, Podoltsev NA, Huntington SF, Gore SD, Davidoff AJ (2017) Hypomethylating agent therapy use and survival in older patients with chronic myelomonocytic leukemia in the United States: a large population-based study. Cancer 123:3754-3762

Zhou GB, Zhang J, Wang ZY, Chen SJ, Chen Z (2007) Treatment of acute promyelocytic leukaemia with all-trans retinoic acid and arsenic trioxide: a paradigm of synergistic molecular targeting therapy. Biol Sci 362:959-971

Zou W, Zhang DE (2006) The interferon-inducible ubiquitin-protein isopeptide ligase (E3) EFP also functions as an ISG15 E3 ligase. J Biol Chem 281:3989-3994 